\title{
AN INVESTIGATION OF MEDIATIONAL PROCESS IN SOCIAL LEARNING DURING ONLINE LANGUAGE LEARNING
}

(iD) Ira Syaqira
Sukimin $^{+}$
(iD Noor Hanim
Rahmat $^{2}$
(D) Mok Soon Sim
(D) Mazlen Arepin
(iD Nur Sherina Zainal
Abidin
(iD Haeza Haron

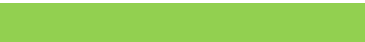

Article History

Received: 9 February 2021 Revised: 11 March 2021

Accepted: 14 April 2021

Published: 17 May 2021

Keywords

Social learning

Mediational process Learner-to-learner

Learner-to instructo

Learner-to-content.

\author{
${ }^{1,5}$ Akademi Pengajian Bahasa, Univeristi Teknologi MARA Cawangan \\ Johor, Kampus Segamat, Johor Darul Ta'zim, Malaysia. \\ 'Email:irasyaqira@uitm.edu.my \\ ${ }^{5}$ Email:nursherina@uitm.edu.my \\ ${ }^{2,3}$ Akademi Pengajian Bahasa, Universiti Teknologi MARA, Shah Alam, \\ Selangor, Malaysia. \\ 'Email:patanim@gmail.com \\ 'Email:moksoon@uitm.edu.my \\ ${ }^{4}$ Fakulti Pendidikan, Kampus Puncak Alam, Universiti Teknologi MARA, \\ Selangor Darul Ehsan, Malaysia. \\ ‘Email:jasmazlen@uitm.edu.my \\ ${ }^{6}$ School of Languages, Literacies, and Translation, Universiti Sains \\ Malaysia, Penang, Malaysia. \\ ${ }^{6}$ Email: haezaharon@gmail.com

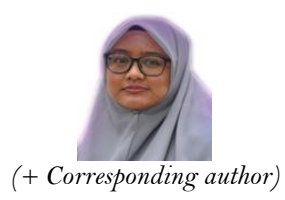 \\ (+ Corresponding author)
}

$A B S T R A C T$

Online learning has become a new trend in the world. To teach online effectively, the instructors have to improvise their course content. Learners have mixed feelings over online learning, some of them prefer the face-to-face teaching; but some are comfortable with the online teaching mode. Previously, the success of language teaching has always depended on face-to-face interaction. However, language is taught online now. Therefore, this study was carried out to investigate the mediational process in social learning during online language learning. 111 diploma, bachelor degree and postgraduate students had participated in this quantitative study in a public university in Malaysia. The instrument used is a questionnaire with 29 items. This study examines the influence of online language learning on learner-to-learner, learner-to-instructor, learner-to-content interaction and mediational process. The results show there is a significant difference in education level. Findings in this study reveals that support from peers plays a crucial role as it prevents students from dropping out of the course. The students prefer teaching style that involves their active participation. The findings also indicate that students find it is important to get an overview of the content before the class begins. Lastly, learning motivation increases when instructor gives good comments during online lessons. Learners also need to learn to be more responsible to make sure their online learning time is filled with successful learning and interactions.

Contribution/ Originality: This paper's main contribution is finding that online learning is a form of mediational process for learners. Learners get the opportunity to engage through learner-to-learner, learner-toinstructor, as well as learner-to content interactions.

\section{INTRODUCTION}

COVID-19 has changed the global environment in many ways. One inevitable change is the way teaching and learning is done. Institutions are sprouting with new and old courses online. Many online courses serve to facilitate 
many parties during this trying time of the pandemic. Researchers have conducted studies to investigate the benefits on online learning. Mukhtar, Javed, Arooj, and Sethi (2020) and also Luaran, Samsuri, Nadzri, and Rom (2014) found that online learning gives learners flexibility. Learners are able to do remote learning. Their learning time and content is made accessible to them anytime and anywhere. Mukhtar et al. (2020) also found that online learning allows more student-centred environment. Students feel comfortable with self-directed learning.

However, sometimes online learning may not be as helpful to all learners. The study by Stark (2019) found that online learning is strongly correlated with the course performance than learning strategies. This means the teacher plays an important role in online learning. Stark (2019) also reported that online learning success differ levels of students.

This study is therefore done to investigate further other factors that influence online learning particularly in the learning of language. Specifically, this study is done to answer the following research questions:

(a) Is there any significance difference for learner-to-learner interaction, learner-to-instructor, and learner-tocontent interaction across education level?

(b) How does learning language online influence learner-to-learner interaction?

(c) How does learning language online influence learner-to-instructor interaction?

(d) How does learning language online influence learner-to-content interaction?

(e) How does learning language online influence mediational process?

\section{LITERATURE REVIEW}

\subsection{Introduction}

This section discusses the theory of social learning, how language is learnt, language strategies used by learners, motivation and demotivation for online language learning; however, past studies on online language learning.

\subsection{Social learning Theory}

The theory of social learning states that other factors are involved in the language learning process. Learners depend on their surrounding and backgound knowledge to make sense of the world around them (Rahmat, 2016). Social learning theory is the link between traditional learning (that is through behaviourism) and cognitive approach. Bandura (1977) observed that when people learn, they process the information based on the relationship between their behaviour and the consequences. This means observational learning cannot take place unless the cognitive process is also at work. People do not model a behaviour automatically. They have some thought before they imitate. This consideration is called mediational process. This process occurs in four stages Figure 1; (a) attention, (b) retention, (c) reproduction, and (d)motivation. Social learning begins when the learners pay attention to the content of the material. Next, learners make effort to retain the knowledge gained using various strategies. When the learner is ready, he/she will be able to reproduce the learned knowledge. Continued motivation in the learning process can help learners plan for future learning.

\subsection{How Language is learnt}

Based on different approaches and research paradigms, beliefs in language learning have a pivotal role in several empirical studies. A great deal of individual variation is the subject to language and speech learning that is widely understood by scholars. Like all education, language teaching has become an increasing matter for public debate and the state has had its eye on it since the nineteenth century (McLelland, 2017). Learners have different ideas about the language learning process based on their prior language experiences on learning and personal knowledge. These assumptions, perceptions, expectations, notions and attitudes refer to the language itself, for 
example, language learning's nature, useful learning strategies, and the methodology for successful teaching, the ability for learners' language learning and success or failure's attributions.

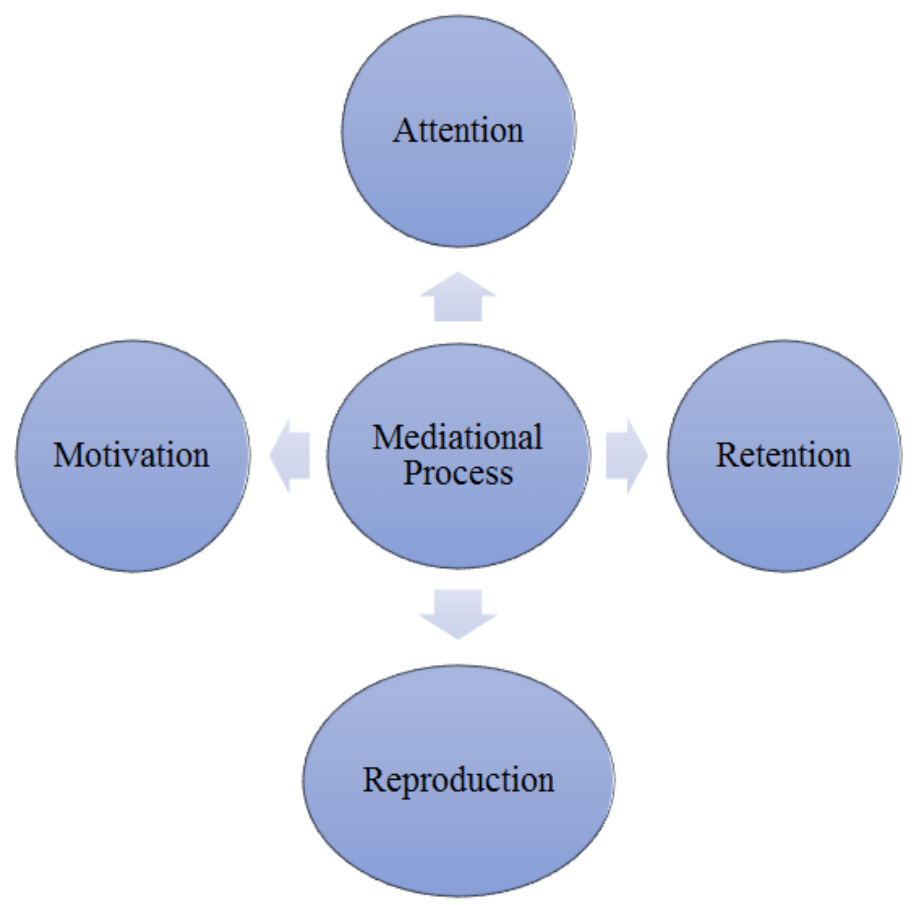

Figure-1. Considerations for successful mediational process.

Three broad dimensions of beliefs can be identified as: language learning beliefs, beliefs about self and beliefs about the learning situation. Learner beliefs have various sources: The same as other socialization aspects, this acquired knowledge may be done unconsciously, the outcome of observation and imitation, as learners listen to teachers consciously, the advice on how to learn are provided by and peers and parents. The recent researching belief approaches emphasize that they are dynamic, socially constructed and context-dependent: 'beliefs are recognized as part of students' experiences and interrelated with their environment'. The research indicated by Lodhi, Sahar, Qayyum, Iqbal, and Shareef (2019) was that positive outcomes are fostered by supportive schools by promoting students' sense of connectedness. Interchangeably, these terms are used here to refer to the sense of that the students' have of being in a close, respectful relationship with peers and adult at school. Therefore, fostering academic success is meant by building it in a school community.

With regards to learner beliefs, research has been conducted with different language learners with group of different ages as an approach to learn in the natural way. In regards of literature, a considerable amount has been published on factors that affect language learning such as groups of different ages, and different cultural settings and a variety of learner views has been brought to the surface. For instance, language learning is influenced by the age factor as this view is supported by Kurdziel, Mantua, and Spencer (2017) states that among older people, the decline in language ability is slower than the decline in global memory. In addition, in terms of raw vocabulary, older individuals have possession of them even if compared with adults of young generation who are well-educated. On the other hand, formal aspects of the language like grammar and vocabulary always tend to be focused on certain learners. Vocabulary learning is an essential part in learning a foreign language as it emphasizes on the meanings of new words, whether in books or in classrooms. To language teaching, it is also central and is of the utmost importance to a learner of the language. A learning intention's absence or presence does not have a decisive role to play as vocabulary acquisition is first and foremost determined by the processed new word's nature and frequency. 


\subsection{Online Language Learning Strategies}

With digital tools aiding the new age, and through classroom strategies that are technology enabled, language learning is actively involved with students and communication skills and creativity can be developed. A strategy to language learning in a online classroom that is functional does not provide fixed recipes for language activities when advocating language teaching. Rather it is concerned with giving instruction about the development of effective language resources for particular purposes, and giving it at the point of need within the context of real, meaningful language use. Because in this way, adjustments and modifications can be made by the students in regards to their performance to better meet contextual demands and different situations, and thus improving their learning standard eventually. Other than helping them with their language skills, digital media assists the students, and students are able to visualize and grasp a concept much easier. The implication is that immediate attention must be given to the classroom practices to the interactive digital media that students' access and assist them so that their language skills can be developed accordingly. It is undeniable that positive strategies with interactive digital media can and does make a difference in the behaviour of a classroom, but their application are not rigid, and according to $\mathrm{Li}$ (2019) there is a lasting development and complement of the usage in their classroom.

One of the online learning's prominent challenge is how to help in autonomous student learning, persistently and actively. The consensus that any level of success related to online learning requires an autonomy that is relatively in a high degree, including learning practices that are self-directed and the ability to manage one's own time and learning pace. For instance, online learning strategy such as self-regulated learning or SRL is referred as "an active, constructive process whereby goals are set by the learners for their learning and then attempt to monitor, regulate, and control their cognition, motivation, and behavior, guided and constrained by their goals and contextual features of the environment" Looking beyond the course of traditional language, it is shown in several recent articles that concerning technology-enhanced learning contexts, SRL can have positive impacts including digital reading-annotation systems,learning environments via mobile (Zheng, 2016) and online collaborative learning. However, the examined studies of the particular strategies, including cognitive strategies (e.g., goalsetting) and metacognitive strategies (e.g., time management and help-seeking), were all domain-general. Online learning researches also tend to focus on strategies that are domain-general, and to report that the SRL strategies used by the students are critical to their success being achieved. Compared with classrooms that are face-to-face, in terms of online learning for students, more autonomous control over their learning behaviour is required, and students' motivation are found to have increased by the online learning format, which in turn significantly predicts their achievement. Online-learning satisfaction positively and significantly correlates with students' use of SRL strategies, as demonstrated by previous studies (Kuo, Walker, Schroder, \& Belland, 2014).

\subsection{Online Learning Motivation and Demotivation}

Learners are motivated to learn online due to several factors. Stark (2019) reports that instead of learning strategies, learners are motivated by the course performance. Course performance includes the activities that the instructors planned in the online sessions. Another study by Rahmat, Sukimin, Mok, Anuar, and Mohandas (2021) found that online learning motivation are influenced by four main factors and they are; (a) attention, (b) relevance, (c) confidence and (d) satisfaction Figure 2. Attention can either be negative or positive. Negative attention refers to the life commitments of the learners. Positive attention refers to the support from the peer community. Next, relevance refers to the module support that the instructor prepares for the online course. When learners gain confidence in their learning, they become satisfied with the learning activities. 


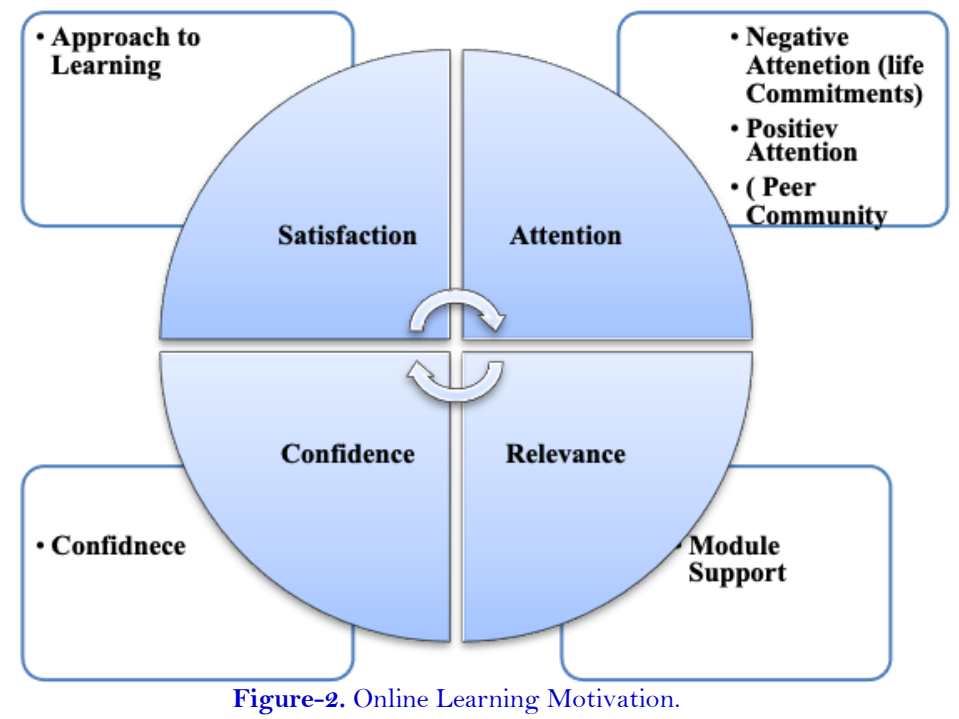

On the other hand, there are also some factors that demotivate learners to learn online. Kuama and Intharaksa (2016) found that difficulties in online learning can be categorized into three; (a) cognition, (b) metacognition, (c) technical anxiety, and (d) learning styles. They claim that cognitively, some learners have basic problems with making decisions during online learning. Non-face-to-face learning does not allow depend on the teacher in class to help them solve learning problems immediately. Metacognitively, learners face challenges with their planning in learning. They may get the freedom of having no specific class schedule; however, this becomes a disadvantage when learners fail to follow planned schedule for classes and assignments deadlines. Next, some learners may have computer anxiety and this can affect their achievement. Finally, learning styles differ across learners. Some prefer studying with peers, some are comfortable being independent, but there are others who need more assistance faceto-face.

\subsection{Past Studies}

This pandemic has encouraged researchers to look into how learners perceive about online learning. The study by Wahid, Rahmat, Dzuradeen, and Kadir (2020) examined engagement methods during online learning. This study used a set of survey to collect data. Items in the survey look into the functions of learner-to-learner, learnerto instructor, and learner-to-content engagement in online learning. The survey consists of 24 items. 55 students from a publica university in Malaysia responded to the survey. Findings revealed that the functions of learner-tolearner, learner-to instructor, and learner-to-content engagement. Findings of the study learner-to=instructor plays the most significant role in online learning classrooms. Next, the study by Kuama and Intharaksa (2016) investigated online language learning strategies (OLLS) and how they influence the learning outcomes of successful and unsuccessful learners. .364 university students were divided into 2 groups- 262 successful online language (SLs) and 84 unsuccessful online language students (Uls). Participants rated their use of three OLLS: cognitive, metacognitive, resource management, and rated their perceptions of an online learning. The main instruments were an OLLS questionnaire, and a stimulated recall with an in-depth interview. Findings showed that there was significant difference between SLs and ULs for metacognitive strategies. Findings also showed that there was no significant differences SLs and Uls for resources management strategies. The results suggest that low English proficiency students lacked online learning skills and experiences in self-directed learning. They may not be ready for learning English online.

Learning online demands learners' to constantly stay motivated. Hartnett (2012) investigated the motivation of pre-service teachers on online learning. Data was collected from self-report motivation data, achievement and online usage statistical data with asynchronous discussion, as well as forum transcripts. Findings reveal various 
motivating factors such as specific environment. Instructors need to use complex ways to motivate to learn, online. Findings focus on the need to be cautious about online instructions as their use can affect students' motivation to learning. Next the study by Stark (2019) compared the motivations and learning strategies of online and face-toface students. The instrument used is Motivated Strategies for Learning Questionnaire by Pintrich, Smith, Garcia, and McKeachie (1993). Findings show that online students reported lower levels of motivation compared to faceto-face students. The motivation variables were more strongly correlated with course performance compared to learning strategies, particularly for online courses.

\section{METHDOOLOGY}

111 students from diploma, bachelor degree and postgraduate participated in this quantitative study carried out in a public university in Malaysia. The instrument used is a questionnaire with 29 items excluding the demographic profiles. The items in the questionnaire is adapted from Wahid et al. (2020) and Bandura (1977). Section A is demographic profiles. Section B has 6 items on learner-to-learner interaction. Section C has 7 items on learner-toinstructor interaction. Section D has 7 items on earner-to-content interaction and Section E has 9 items on Mediational process. SPSS analysis of the instrument reveals a Cronbach alpha of .943 thus showing the reliability of the instrument (Glen, 2021).

Cronbach alpha

Table-1. Reliability Statistics.

\begin{tabular}{c|c|c}
\hline \multicolumn{3}{c}{ Table-1. Reliability Statistics. } \\
\hline Reliability Statistics \\
\hline Cronbach's Alpha & Cronbach's Alpha based on standardized items & N of Items \\
\hline 0.941 & 0.943 & 29
\end{tabular}

Data is collected via goggle form and analysed using SPSS version 26. Findings is presented based on the research questions using independent $\mathrm{T}$-test and also in the form of percentages and mean scores.

\section{FINDINGS}

\subsection{Introduction}

This chapter provides findings on demographic profile, learner-to-learner interaction, learner-to-instructor interaction, learner-to-content interaction, and mediational process. The findings provide answers to all five research questions of this study.

\subsection{Findings on Demographic Profile}

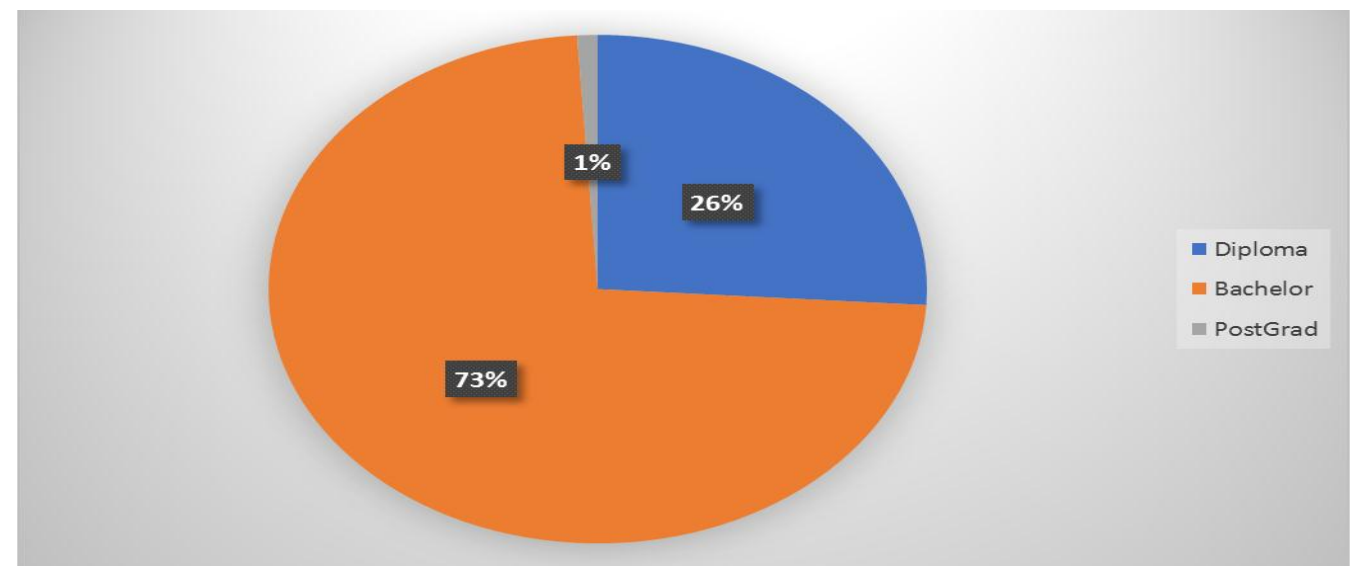

Figure-3. Percentage for respondents' education level 
Based on Figure 3, 73 percent of the respondents are bachelor students while 26 percent respondents are diploma students. Only one percent out of 113 respondents is a postgraduate student.

Research Question 1: Is there any significant difference for learner-to-learner interaction, learner-to-instructor, and learner-to-content interaction across education level?

Table-2. Results of Independent T- Test comparing diploma and bachelor for learner-to-learner interaction.

\begin{tabular}{l|c|c|c|c|c|c}
\hline Results & & \multicolumn{4}{|c}{ Independent T-Test } \\
\hline & & $\boldsymbol{n}$ & $\boldsymbol{x}$ & SD & $\boldsymbol{t}$ & $\boldsymbol{p}$ \\
\hline \multirow{2}{*}{$\begin{array}{l}\text { Learner-to-learner } \\
\text { interaction }\end{array}$} & Diploma & 29 & 4.24 & 0.55 & \multirow{2}{*}{-2.41} & \multirow{2}{*}{.02} \\
\cline { 2 - 6 } & Bachelor & 83 & 4.48 & 0.45 & \\
\hline Note: *T-test significant is at .05 (2 tailed)
\end{tabular}

Table 2 indicates the result of mean score and standard deviation between diploma and bachelor students for learner-to-learner interaction; $(\bar{x}=4.24)$ for diploma students and $(\bar{x}=4.45)$ for bachelor students. The Independent T-Test comparing between diploma students and bachelor students reports that there is statistically significant difference in the mean score $(t(110)=-2.41), p=0.02)$ at the 0.05 level. This means it would make a difference in how learners interact among themselves depending on their level of studies.

Research Question 2: How does learning language online influence learner-to-learner interaction? Learner-tolearner interaction is done through student collaboration and community support. Q6-8 refer to questions on student collaboration and Q9-11 refer to community support.

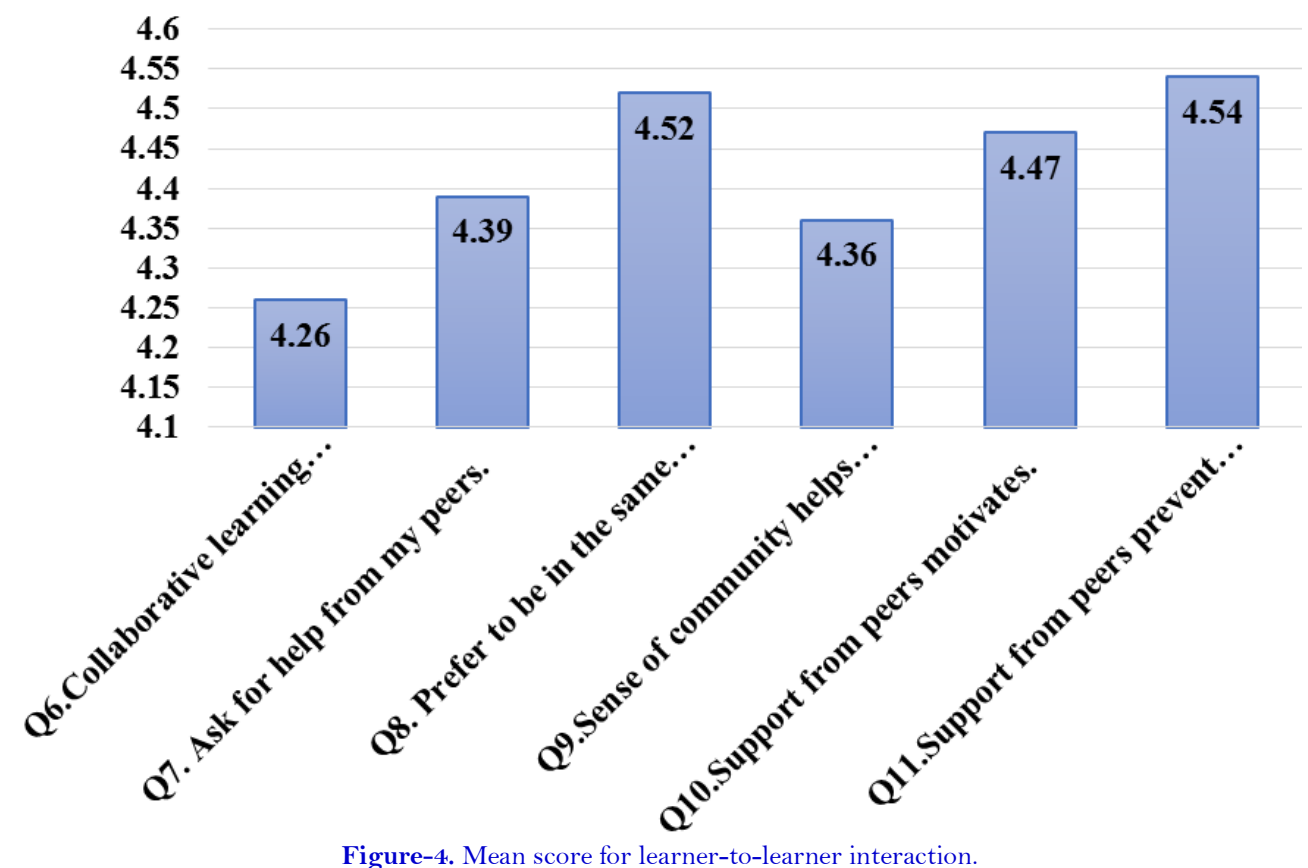

Based on Figure 4, Question 11 (support from peers prevents students from dropping out of the course) records the highest mean which is 4.54. The lowest mean, 4.26 is recorded by Question 6 (collaborative learning promotes peer-to-peer understanding). This could mean that online learning gave less opportunity for learners to understand one another better.

Research Question 3: How does learning language online influence learner-to-instructor interaction? Learnerto-instructor interaction can take place through the teaching strategies used by the instructor as well as the efforts taken by them (the instructors) to communicate with the learners. Q12-Q15 refer to teaching strategies, while Q16Q18 refer efforts to communicate. 


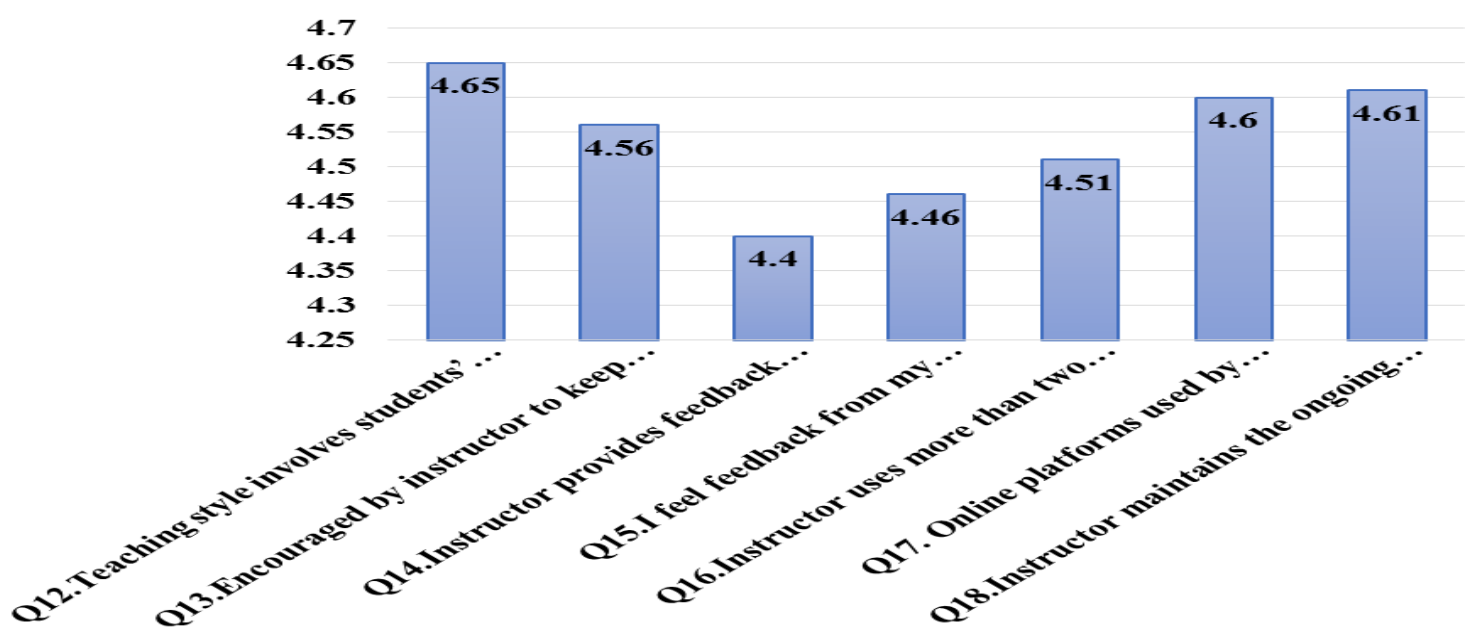

Figure-5. Mean Score for Learner-to-Instructor Interaction.

As shown in Figure 5, Question 12 (Teaching style involves students' active participation) records the highest mean which is 4.65. The lowest mean, 4.40 is recorded by Question 14 (Instructor provides feedback from previous assessment).

Research Question 4: How does learning language online influence learner-to-content interaction? Learner-toContent refers to (a) learning activities and also (b) user's interface. Q19-Q23 refers to learning activities while Q24 and Q25 refer to user interface.

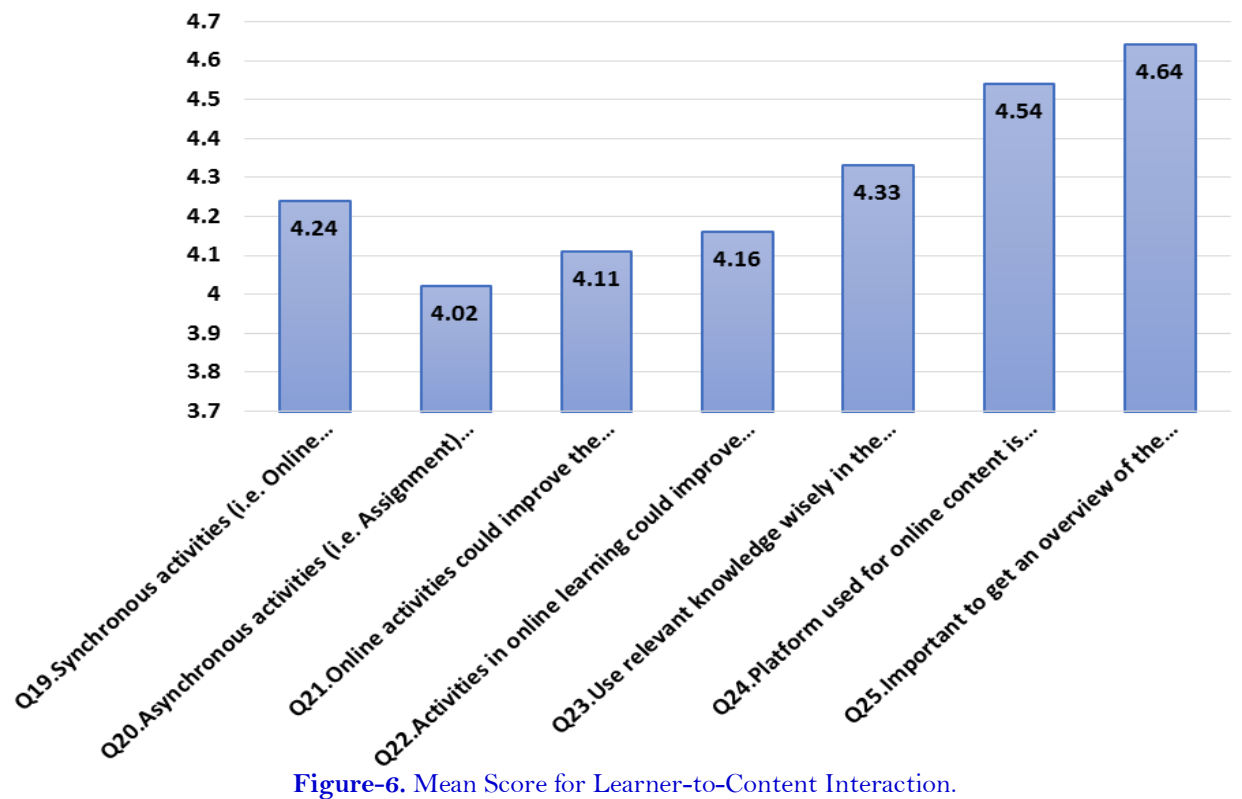

Referring to Figure 6 above, Question 25 (Important to get an overview of the content before the class begins) records the highest mean which is 4.64. The lowest mean, 4.02 is recorded by Question 20 (Asynchronous activities (i.e. Assignment) offer immediate assistance).

Research Question 5: How does learning language online influence mediational process? There are four stages in mediational process. The first stage is (a) attention (Q26-Q28). The second stage is (b) retention (Q29 \& Q30). The third stage is (c) reproduction (Q31 \& Q32). The fourth stage is (d) Motivation (Q33 \& Q34). 


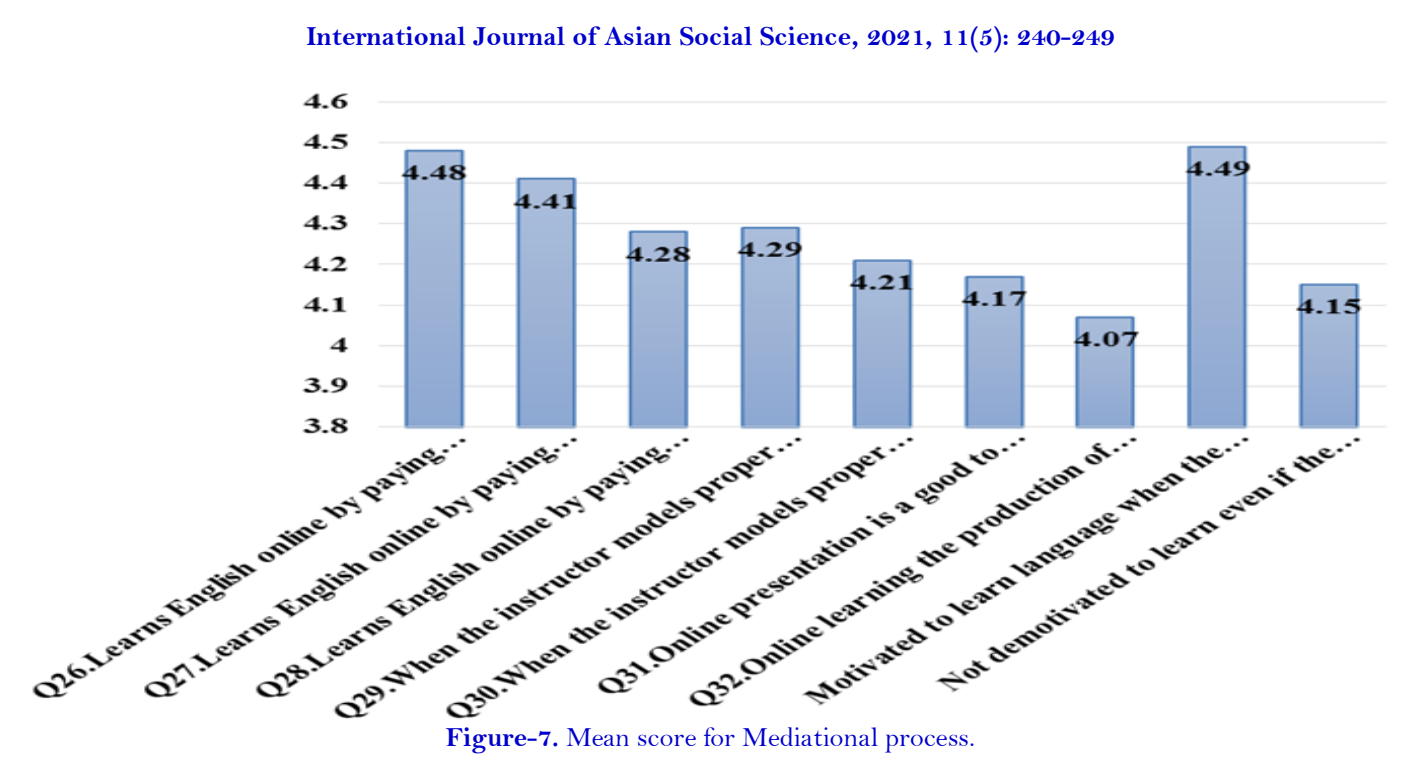

Based on Figure 7, Question 33 (Motivated to learn language when the instructor gives good comments during online lessons) records the highest mean which is 4.49. The lowest mean, 4.07 is recorded by Question 32 (Online learning the production of good written language.).

\section{CONCLUSION}

\subsection{Summary of Findings and Discussion}

There is a significant difference in education level, which means the acceptance of online language learning differs across diploma, bachelor, and postgraduate students. The studies by Pintrich et al. (1993) and Kuama and Intharaksa (2016) both found that the acceptance of online classes differ not only across courses, content, but also different levels of learners. Findings in this study reveals that support from peers plays a crucial role as it prevents students from dropping out of the course. This is also reported by Stark (2019) who emphasized on learners' interaction in online classes. This is again supported by Zheng (2016) who suggested collaborative online activities. As for learner-to-instructor, findings of this study reveal students prefer teaching style that involves their active participation. The study by Kuo et al. (2014) focused on teaching style that encourage self-regulate dlearning. Learners are taught to be independent. Based on the findings, it is also revealed that students find it important to get an overview of the content before the class begins. Knowing the content beforehand gives the learners confidence during online sessions. This is also reported by Rahmat et al. (2021) who felt that student are motivated to learn online when they have confidence. Lastly, learning motivation increases when instructor gives good comments during online lessons. According to Rahmat et al. (2021) motivation in online learning can also come from the positive comments they receive both from peers and teachers.

\subsection{Pedagogical Implication and Suggestion for Future Research}

In many ways online teaching seems similar to face-to-face teaching. Nevertheless, the experiences of both instructors conducting online language lessons and the learners attending online sessions would prove that there are many factors that need to be taken into consideration to make lessons successful. Instructors need to take into three types on interaction in online classes: learner-to-learner, learner-to-instructor, and even learner-to-content interaction. Learners also need to learn to be more responsible to make sure their online learning time is filled with successful learning and interactions. Future research can focus on the experiences of learners as well experiences of instructors teaching language online classes. Interviews could be done to gain deeper insights into online learning experiences. 
Funding: This study received no specific financial support.

Competing Interests: The authors declare that they have no competing interests.

Acknowledgement: All authors contributed equally to the conception and design of the study.

\section{REFERENCES}

Bandura, A. (1977). Social learning theory. Englewood Cliffs, NJ: Prentice Hall.

Glen, S. (202 1). Cronbach's Alpha: Simple definition, use and interpretation" From StatisticsHowTo.com: Elementary Statistics for the rest of us! Retrieved from: https://www.statisticshowto.com/probability-and-statistics/statisticsdefinitions/cronbachs-alpha-spss/.

Hartnett, M. (2012). Relationships between online motivation, participation, and achievement: More complex than you might think. Journal of Open, Flexible and Distance Learning, 16(1), 28-41.

Kuama, S., \& Intharaksa, U. (2016). Is online learning suitable for all english language students. PASAA, 52, 53-78.

Kuo, Y.-C., Walker, A. E., Schroder, K. E., \& Belland, B. R. (2014). Interaction, Internet self-efficacy, and self-regulated learning as predictors of student satisfaction in online education courses. The Internet and Higher Education, 20, 35-50.Available at: https://doi.org/10.1016/j.iheduc.2013.10.001.

Kurdziel, L. B., Mantua, J., \& Spencer, R. M. (2017). Novel word learning in older adults: A role for sleep? Brain and Language, 167, 106-113.Available at: https://doi.org/10.1016/j.bandl.2016.05.010.

Li, H. (2019). Language learning strategies for digital classrooms. International Journal of English Literature and Social Sciences, 4(3), 635-640.Available at: https://doi.org/10.22161/ijels.4.3.13.

Lodhi, M. A., Sahar, A. H., Qayyum, N., Iqbal, S., \& Shareef, H. (2019). Relationship of school environment and English language learning at government schools. Public Administration Research, 8(1), 1-13.Available at: https://doi.org/10.5539/par.v8n1p1.

Luaran, J., Samsuri, N. N., Nadzri, F. A., \& Rom, K. B. M. (2014). A study on the student's perspective on the effcetiveness of using e-leraning. Procedia Social and Behvioural Sciences, 123 139-144.

McLelland, N. (2017). Teaching and learning foreign languages: A history of language education, assessment and policy in Britain. London: Routledge. Retrieved from: https://www.routledge.com/Teaching-and-Learning-ForeignLanguages-A-History-of-Language-Education/McLelland/p/book/9780367177911.

Mukhtar, K., Javed, K., Arooj, M., \& Sethi, A. (2020). Advantages, limitations and recommendations for online learning during COVID-19 Pandemic Era. Pakistan Journal of Medical Sciences, 36(v), 27-31.

Pintrich, P. R., Smith, D. A., Garcia, T., \& McKeachie, W. J. (1993). Reliability and predictive validity of the motivated strategies for Learning Questionnaire (MSLQ). Educational and Psychological Measurement, 53(3), 801-813.

Rahmat, N. H. (2016). Audience awareness in academic writing among undergraduates. Jurnal Pendidikan Bahasa dan Sastera, $16(1), 88-95$.

Rahmat, N. H., Sukimin, I. S., Mok, S. S., Anuar, A., \& Mohandas, E. S. (2021). Online learning motivation and satisfaction: A case study of undergraduates vs postgraduates. International Journal of Asian Social Science 11(2), 88-97.

Stark, E. (2019). Examining the role of motivation and learning strategies in student success in online versus face-to-face courses. Online Learning Journal, 23(2), 234-251.

Wahid, H. S. A., Rahmat, N. H., Dzuradeen, N. S., \& Kadir, N. A. (2020). Are students engaging in online classrooms? European Journal of Education Studies, 7(12), 202-221.

Zheng, L. (2016). The effectiveness of self-regulated learning scaffolds on academic performance in computer-based learning environments: A meta-analysis. Asia Pacific Education Revierw, 17, 187-202.Available at: https://doi.org/10.1007/s12564-016-9426-9. 